\title{
A Comparative Study of Three Echelon Inventory Optimization using Genetic Algorithm and Particle Swarm Optimization.
}

\author{
Anshul Gupta, Vishal Narayan, Abhishek Raj, Harsh, and D.Nagaraju
}

\begin{abstract}
Supply chain is an integral part of the operations management and became a significant concept for overall profitability of industrial scenario. It consists of several levels in which material flows through various stages to reach the end customer. A three level supply chain consists of a manufacturer, distributor and retailer, who are the cost bearers. It is necessary to have a coordinated approach between the tiers so that the chain is timed accurately for least inventory and minimum cost consequently maximum profits. In this paper, we consider a coordinated three echelon supply chain with a single manufacturer supplying a single type of product to single distributor and then to a single retailer. A mathematical model is developed for the coordinated supply chain under consideration and it is solved using Particle Swarm Optimization (PSO) algorithm and Genetic Algorithm (GA) for optimal values of decision variables and objective function. A numerical example is posed and the results obtained herein are compared for these techniques.
\end{abstract}

Index Terms-Genetic algorithm, multi-echelon inventory problem, particle swarm optimization, supply chain

\section{INTRODUCTION}

\section{A. Supply chain}

The concept of supply chain management was first introduced by Houlihan as presented in [1] and that the role of customer and supplier is played by every member in a supply chain system and the main target of supply chain management is to has since been a major advancement in logistics field. Reference [2] describes supply chain management as a unifying method for planning and manipulating the material flow from suppliers to end-users. Reference [3], [4] discuss the conceptintegrate upstream and downstream suppliers to enhance theoverall efficiency of the supply chain to meet customer demand.

A MIP model proposed in [5], proposed supply chain which is divided into stages and each stage representing an operation (the sourcing of a component, the assembly of a sub-assembly or the final product, and the shipment of a product to customers) or an activity that could be implemented by alternative resource options.

Manuscript received March 24th, 2012; revised May 9, 2012.

A. Gupta, V. Narayan, and A. Raj are with Mechanical engineering student in Vellore institute of technology, Vellore-632014, Tamil Nadu, India (email: anshulg.1989@gmail.com; vishal_n1990@yahoo.com; abhishek.one.raj@gmail.com).

Harsh is with Computer science engineering student in Vellore institute of technology, Vellore-632014, Tamil Nadu, India (email: harsh.einstein@gmail.com).

D. Nagaraju is with Manufacturing Division, School of Mechanical and Building Sciences, VIT University, Vellore-632014, Tamil Nadu, India (email: deganagaraju@vit.ac.in).

\section{B. Genetic Algorithm (GA)}

Genetic algorithm (GA), one of the notable random evolutionary search algorithms, was developed by John Holland in the late sixties. The ease of usability and larger number of applications aided GA to be applied in various optimization and search queries and has emerged as one of the promising methods to provide explanations for complex problems discussed in[6]-[9].

A certain population of strings, which encodes candidate solutions (called individuals) to an optimization problem, evolves toward generating better solutions. The operation of evolution starts from a population of arbitrarily generated individuals and takes place in generations. The fitness value of each individual in the population is calculated in every generation. Multiple individuals are stochastically chosen from the current population (based on their fitness data), and they are modified (recombined and possibly randomly mutated) to form a new population. The new population generated is utilized in the next iteration of the algorithm specified. When a highest number of generations have been produced or a satisfactory fitness level has been reached for the population, the algorithm culminates.

Reference[10] gives development a Genetic Algorithm (GA) based coordination algorithm which is able to coordinate the agent'sinteractions to optimise the supply chain designs dynamically. A GA based process to design a four-echelon supply chain (suppliers, plants, warehouses, and customers) was introduced in [11]. Genetic Algorithmshas been applied in several engineering fields as presented in [11]-[15]. Genetic algorithm has also been excessively used as an alternative to exhaustive methods to solve combinatorial problems as a result of its limiting complexity.

\section{Particle Swarm Optimization (PSO)}

Reference [16], [17] stated that PSO is a simple and usable method to calculate the optimization problems. Particle Swarm Optimization was introduced by Eberhart and Kennedy in [18] as an optimal algorithm which is based on the concept of social demeanour of bird flocking. The swarm consists of particles and the each particle is an individual. Every position in the problem solution space or the search space is an affiliated solution to the problem describing the way particles cooperate to identify the best position (best solution) in the search space (solution space).

With consecutive iterations, particles travel toward the pbest position and gbest position. The pbest position is the best position calculated by each particle so far specific to each particle in a specific iteration whereas the gbest position is the best position generated by the swarm. The 
particle motion is a function of its velocity that is arbitrarily calculated toward pbest and gbest positions. The equations given below update the velocity and position of for each particle $\mathrm{p}$ with dimension $\mathrm{q}$.

$$
\begin{gathered}
v_{p q} \leftarrow w \times v_{p q}+c_{1} \times \operatorname{rand} 1 \times\left(\text { pbest }_{p q}-x_{p q}\right) \\
+c_{2} \times \operatorname{rand} 2 \times\left(\text { gbest }_{q}-x_{p q}\right) \\
x_{p q} \leftarrow x_{p q}+v_{p q}
\end{gathered}
$$

Here, $\mathrm{v}_{\mathrm{pq}}$ and $\mathrm{x}_{\mathrm{pq}}$ are the velocity and position respectively of particle $\mathrm{p}$ on dimension $\mathrm{q}$. Also, pbest $_{\mathrm{pq}}$ is the pbest position of particle $\mathrm{p}$ on dimension $\mathrm{q}$, and gbest $_{\mathrm{q}}$ is the gbest position of the swarm on dimension q.A higher value of $w$ i.e. inertia weight gives that the particles achieve high velocities and vice versa. Particles prefer moving near towards pbest position or gbest position based on constants $\mathrm{c}_{1}$ and $\mathrm{c}_{2}$. The rand 1 and rand 2 are the arbitrary variables between 0 and 1 .

\section{MATHEMATICAL MODELING}

In accordance with the underlying assumptions, we constrain and define the mathematical model. This mathematical model is used to define the nature of the problem in terms of cash flow in the supply chain through various levels. These amounts are represented in terms of mathematical concepts and formulated in the model proposed below.A numerical illustration posed solves the model using both Genetic Algorithm and Particle Swarm Optimization and compares the results obtained.

\section{A. Assumptions}

The following features and assumptions are considered for the model.

1) Deterministic demand.

2) Instantaneous replenishment rate.

3) Distributor's inventory is an integer multiple of retailer's inventory.

4) Manufacturer's inventory is an integer multiple of distributor's inventory.

5) No shortages are allowed.

\section{B. Notations}

The notations used in the proposed model are shown as follows.

D Demand rate in units per unit time (Normally one year)

$\mathrm{S}_{\mathrm{R}} \quad$ Retailer's ordering cost (Rs/order)

$\mathrm{S}_{\mathrm{D}} \quad$ Distributor's ordering cost (Rs/order)

$\mathrm{S}_{\mathrm{M}} \quad$ Manufacturer's setup cost (Rs/setup)

$\mathrm{C}_{\mathrm{R}} \quad$ Retailer's unit cost (Rs/unit)

$\mathrm{C}_{\mathrm{D}} \quad$ Distributor's unit cost (Rs/unit)

$\mathrm{C}_{\mathrm{M}} \quad$ Manufacturer's unit cost (Rs/unit)

$\mathrm{q}_{\mathrm{R}} \quad$ Retailer's ordering quantity in units

$\mathrm{q}_{\mathrm{D}} \quad$ Distributor's ordering quantity in units

$$
\left(\mathrm{q}_{\mathrm{D}}=\delta \mathrm{q}_{\mathrm{R}}\right)
$$

$\mathrm{q}_{\mathrm{m}} \quad$ Replenishment quantity at the manufacturer in units

$$
\left(\mathrm{q}_{\mathrm{M}}=\gamma \mathrm{q}_{\mathrm{D}}\right)
$$

$\delta \quad$ The ratio of distributor's replenishment quantity to retailer's replenishment quantity, appropriated to a positive integer.

$\gamma$ The ratio of manufacturer's replenishmentquantity to distributor's ordering quantity, appropriated to a positive integer.

$\mathrm{k}$ Carrying charge or Interest rate in Rs/Re/unit time $\mathrm{P} \quad$ Retailer's selling price (Rs/unit)

$\mathrm{TC}_{\mathrm{R}}\left(\mathrm{q}_{\mathrm{R}}\right) \quad$ Total relevant cost of the retailer (in Rs) expressed in terms of $q_{R}$

$\operatorname{TC}_{\mathrm{D}}\left(\delta, \mathrm{q}_{\mathrm{R}}\right)$ Total relevant cost of the distributor (in Rs) expressed in terms of $\delta, \mathrm{q}_{\mathrm{R}}$

$\mathrm{TC}_{\mathrm{M}}\left(\delta, \gamma \& \mathrm{q}_{\mathrm{R}}\right)$ Total relevant cost of the manufacturer (in Rs) expressed in terms of $\delta, \gamma \& \mathrm{q}_{\mathrm{R}}$

$\mathrm{TC}_{\mathrm{S}}\left(\delta, \gamma \& \mathrm{q}_{\mathrm{R}}\right)$ Total relevant cost of the supply chain (in Rs) expressed in terms of $\delta, \gamma \& \mathrm{q}_{\mathrm{R}}$

\section{Model Formulation}

The annual total relevant cost of the retailer is given by the sum of annual ordering cost and carrying cost at retailer and it can be expressed as,

$$
\mathrm{TC}_{\mathrm{R}}\left(\mathrm{q}_{\mathrm{R}}\right)=\frac{\mathrm{S}_{\mathrm{R}} \mathrm{D}}{\mathrm{q}_{\mathrm{R}}}+\frac{\mathrm{q}_{\mathrm{R}} \mathrm{C}_{\mathrm{R}} \mathrm{k}}{2}
$$

The annual total relevant cost of the distributor is given by the sum of annual ordering cost and carrying cost at distributorand it can be expressed as,

$$
\mathrm{TC}_{\mathrm{D}}\left(\delta, \mathrm{q}_{\mathrm{R}}\right)=\frac{\mathrm{S}_{\mathrm{D}} \mathrm{D}}{\delta \mathrm{q}_{\mathrm{R}}}+\frac{(\delta-1) \mathrm{q}_{\mathrm{R}} \mathrm{C}_{\mathrm{D}} \mathrm{k}}{2}
$$

The annual total relevant cost of the manufacturer is given by the sum of annual ordering cost and carrying cost at manufacturerand it can be expressed as,

$$
\begin{aligned}
& \mathrm{TC}_{M}\left(\gamma, \mathrm{q}_{\mathrm{D}}\right)=\frac{\mathrm{S}_{\mathrm{M}} \mathrm{D}}{\gamma \mathrm{q}_{\mathrm{D}}}+\frac{(\gamma-1) \mathrm{q}_{\mathrm{D}} \mathrm{C}_{\mathrm{M}} \mathrm{k}}{2} \\
& \mathrm{TC}_{\mathrm{M}}\left(\gamma, \mathrm{q}_{\mathrm{R}}\right)=\frac{\mathrm{S}_{\mathrm{M}} \mathrm{D}}{\delta \gamma \mathrm{q}_{\mathrm{R}}}+\frac{\delta(\gamma-1) \mathrm{q}_{\mathrm{R}} \mathrm{C}_{\mathrm{M}} \mathrm{k}}{2}
\end{aligned}
$$

The annual total relevant cost of the supply chain is given by the sum of individual annual total relevant costs at retailer, distributor and manufacturer and it can be expressed as,

$$
\begin{aligned}
\operatorname{TC}_{\mathrm{S}}\left(\delta, \gamma, \mathrm{q}_{\mathrm{R}}\right)=\left(\mathrm{S}_{\mathrm{R}}+\frac{\mathrm{S}_{\mathrm{D}}}{\delta}\right. & \left.+\frac{\mathrm{S}_{\mathrm{M}}}{\delta \gamma}\right) \frac{\mathrm{D}}{\mathrm{q}_{\mathrm{R}}} \\
& +\left(\mathrm{C}_{\mathrm{R}}+(\delta-1) \mathrm{C}_{\mathrm{D}}+\delta(\gamma-1) \mathrm{C}_{\mathrm{M}}\right) \frac{\mathrm{q}_{\mathrm{R}} \mathrm{k}}{2}
\end{aligned}
$$


Equation (7) gives the total relevant cost of the entire supply chain in terms of decision variables and predefined parameters. This equation is optimized for a coordinated supply chain to determine the optimal values of decision variables and objective functionwhereas equations (3), (4) and (6) are optimized individuallyfor optimal values at retailer manufacturer and distributor respectively.

\section{NUMERICAL ILLUSTRATION}

For understanding the quantified effects of the model proposed we take a numerical illustration. This gives us a clear idea as to how PSO is related to GA in terms of practical examples. The following numerical data is considered for the coordinated supply chain problem under consideration to illustrate the presented model.

$$
\begin{array}{ll}
\mathrm{S}_{\mathrm{R}}=\text { Rs 50/order } & \mathrm{C}_{\mathrm{R}}=\text { Rs 140/unit } \\
\mathrm{S}_{\mathrm{D}}=\text { Rs 225/order } & \mathrm{C}_{\mathrm{D}}=\text { Rs 90/unit } \\
\mathrm{S}_{\mathrm{M}}=\text { Rs 450/setup } & \mathrm{C}_{\mathrm{M}}=\text { Rs 50/unit } \\
\mathrm{k}=\text { Rs 0.2/Re/year } & \mathrm{D}=15,000 \text { units }
\end{array}
$$

Applying PSO and Genetic algorithm to the data given above, the equation (7) is solved to obtain the optimal

\begin{tabular}{|c|c|c|}
\hline Item Description & $\begin{array}{c}\text { PSO } \\
\text { Algorithm }\end{array}$ & $\begin{array}{c}\text { Genetic } \\
\text { Algorithm }\end{array}$ \\
\hline $\begin{array}{l}\text { Retailer's replenishment } \\
\text { quantity }\left(\mathrm{q}_{\mathrm{R}}\right)\end{array}$ & 387 units & 369 units \\
\hline $\begin{array}{c}\text { Positive integer (Inventory ratio, } \\
\delta \delta)\end{array}$ & 3 & 2 \\
\hline $\begin{array}{c}\text { Positive integer (Inventory ratio, } \\
\gamma(\gamma)\end{array}$ & 1 & 1 \\
\hline $\begin{array}{l}\text { Distributor's replenishment } \\
\text { quantity }\left(\mathrm{q}_{\mathrm{D}}\right)\end{array}$ & 1161 units & 738 units \\
\hline $\begin{array}{c}\text { Manufacturer's replenishment } \\
\text { quantity }\left(\mathrm{q}_{\mathrm{M}}\right)\end{array}$ & 1161 units & 738 units \\
\hline $\begin{array}{l}\text { Total relevant cost at retailer } \\
\qquad\left(T C_{R}\right)\end{array}$ & Rs 7356/- & Rs 7,198.5/- \\
\hline $\begin{array}{l}\text { Total relevant cost at distributor } \\
\qquad\left(\mathrm{TC}_{\mathrm{D}}\right)\end{array}$ & Rs 9872.9/- & Rs8,614.1/- \\
\hline $\begin{array}{l}\text { Total relevant cost at } \\
\text { manufacturer }\left(\mathrm{TC}_{\mathrm{M}}\right)\end{array}$ & Rs 5813.9/- & Rs7,032.3/- \\
\hline $\begin{array}{l}\text { Total relevant cost of total chain } \\
\qquad\left(\mathrm{TC}_{\mathrm{S}}\right)\end{array}$ & Rs 23,042.9/- & Rs $22,840.6 /-$ \\
\hline
\end{tabular}
values of decision variables and objective function and the results are presented in Table I.

TABLE I: OPTIMAL VALUES OF DECISION VARIABLES AND OBJECTIVE

From the table given above, we depict the comparison of the total relevant cost obtained from the two algorithms under consideration. Here, the inventory ratio obtained is appropriated to a positive integer value depicted in the table. The values of decision variables and objective function are optimized using both methods and is then mapped alongside each other. We see that the total relevant cost of the supply chain as obtained from Genetic Algorithm is lower than that obtained from PSO algorithm.

Fig. 1 shows the continuous decrease in thetotal relevant cost upto a certain value of generations and shows a saturated behaviour with increasing number of generations.

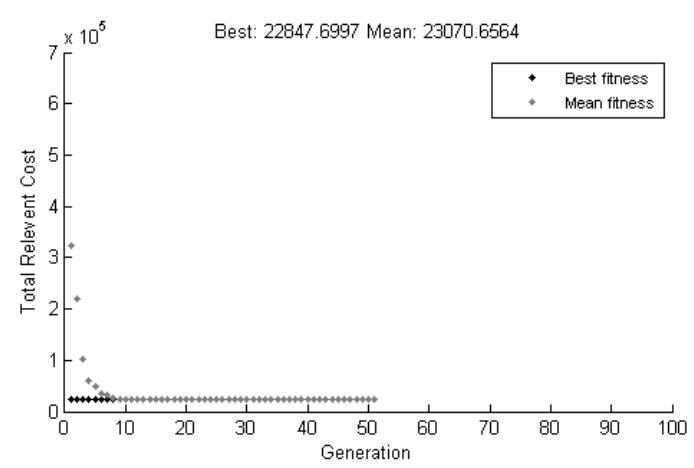

Fig. 1. Graph depicting Total Relevant Cost Vs Generations.

Fig. 2 depicts the optimal values of the inventory ratios and retailer's replenishment quantity. The inventory ratios inscribed are those appropriated to a positive integer as given in Table I.

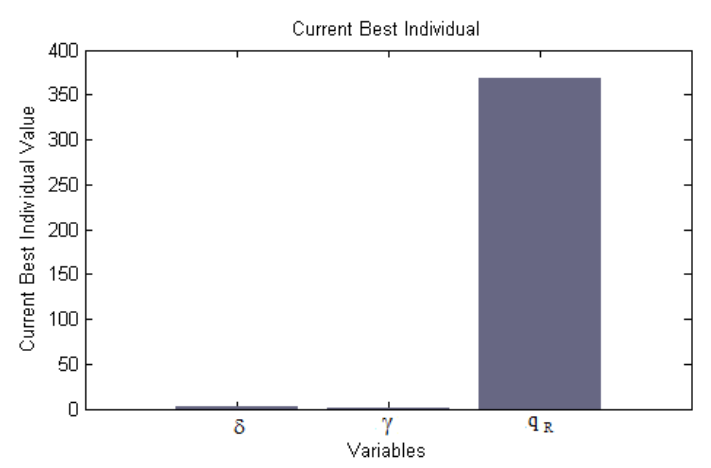

Fig. 2. Graph depicting Current Best Individual ValueVsVariables.

Fig. 3 shows the change in optimal value of the total relevantcost with respect to increasing number of iterations.For lower number of iterations, the solution shows a decreasing trend initially and then becomes steady and for larger iterations, the optimal solution converges to a specific value.

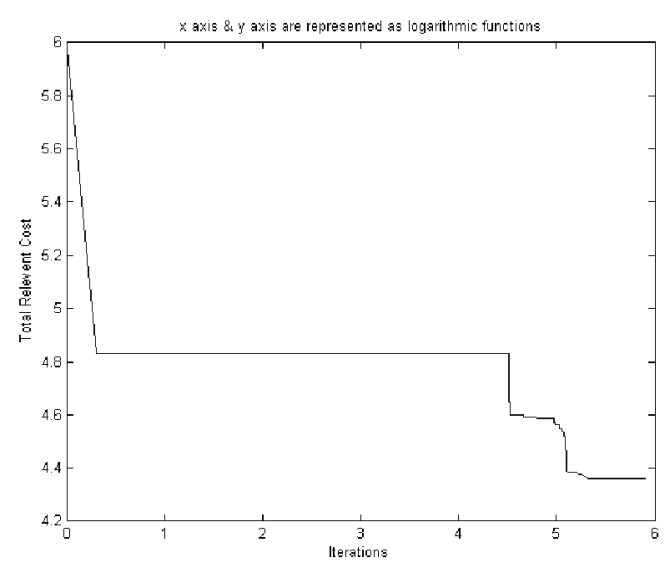

Fig. 3. Graph depicting Total Relevant CostVsIterations (Logarithmic Representation).

In Fig. 4, we infer that in the decreasing pattern the total relevant cost fluctuates initiallyfor up to a certain value of swarm size and then becomes steady with further increase in 
swarm size.

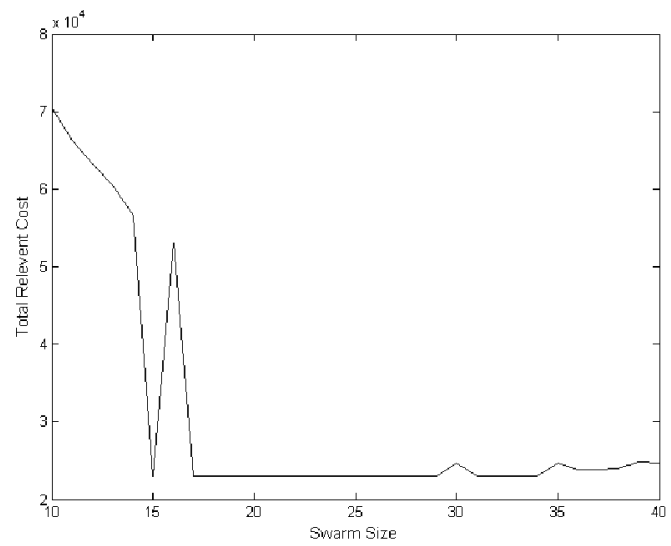

Fig. 4. Graph depicting Total Relevant Cost VsSwarm Size.

\section{CONCLUSIONS}

This paper gives a comparative study along a line of research investigating optimal inventory decisions in a three level supply chain with single manufacturer, single distributor supplying a single type of product to a single retailer. The comparison is based on the algorithm adopted to solve the three echelon problem illustrated by a numerical example.

The model compares the optimized total relevant cost at the manufacturer, distributor and retailer. It is observed that the retailer's replenishment quantity is more in case of particle swarm optimization method along with similar number of shipments as shown by values of positive integers. In addition, it is noted that genetic algorithm gives a lesser output for the total relevant cost of total chain as compared to particle swarm optimization. Hence, it may be concluded from the comparative study that genetic algorithm generates better optimal values for decision variables and objective functions. The scope of the project is cited in industrial applications as optimization of inventory storage in industries.

\section{REFERENCES:}

[1] J. B. Houlihan, "International supply chain management," International Journal Phys. D: Mater. Manage, vol. 15, no. 1, pp. 22-38, 1985.

[2] T. C. Jones and T. C. Riley, "Using inventory for competitive advantage through supply chain management," International Journal Phys. D: Mater, vol. 15, no. 5, pp. 16-26, 1985.

[3] H. Tominaga, T. Nishi, and M. Konshi, "Effect of Inventory control on bullwhip in supply chain planning formultiple companies," International Journal Innov. Comput. Inf. Contro., vol. 4, no. 3, pp. 513-530, 2008.

[4] L. Zhao, L. Qu, and M. Liu, "Disruption coordination of closed-loop supply chain network - models and theorems," Internationa lJournal Innov. Comput. Inf. Contro., vol. 4, no. 11, pp. 2955-2964, 2008.

[5] S. Graves and S. Willems, "Optimizing the supply chain configuration for new products," Management Science, vol. 51, no. 8, pp. $1165-1180,2005$.

[6] Z. Michalewicz, "Genetic Algorithms + Data Structures = Evolution Programs," Second Edition Springer, Berlin, 1994.

[7] D. M. Tate and A. E. Smith, "A genetic approach to the quadratic assignment problem," Computers and Operations Research, vol. 22, no. 1, pp. 78-83, 1995.

[8] C. Mattfeld, "Evolutionary Search and the Job Shop: Investigation on GA for Production Scheduling," Physica-Verlag, Heidelberg, Germany, 1996.
[9] K. R. Ahuja, J. B. Orlin, and A. Tiwari, "A greedy algorithm for the quadratic assignment problem," Computers \& Operational Research, vol. 27, pp. 917-934, 2000.

[10] O. M. Akanle and D. Z. Zhang, "Agent-based model for optimising supply chain configurations," International Journal of Production Economics, vol. 115, no. 2, pp. 444-460, 2008.

[11] F. Altiparmak, M. Gen, L. Lin, and T. Paksoy, "A genetic algorithm approach for multiobjective optimization of supply chain networks," Computers and Indus- trial Engineering, vol. 51, pp. 196-215, 2006.

[12] H. Aytug, M. Khouja, F. E. Vergara, "Use of Genetic Algorithms to solve production and operations management problems: a review," International Journal of Production Research, vol. 41, no. 17, pp. 3955-4009, 2003.

[13] M. Watanabe, K. Ida, and M. Gen, "A Genetic Algorithm with modified crossover operator and search area adaptation for the jobshop scheduling problem," Computers \& Industrial Engineering, vol. 48, no. 4, pp. 743-752, 2005.

[14] E. C. Brown and R. T. Sumichrast, "CF-GGA: A grouping Genetic Algorithm for the cell formation problem," International Journal of Production Research, vol. 39, no. 16, pp. 3651-3669, 2001.

[15] F. T. S. Chan and V. Kumar, "Hybrid TSSA algorithm-based approach to solve warehouse-scheduling problems," International Journal of Production Research, vol. 47, no. 4, pp. 919-940, 2009

[16] C. C. Cui, B. Li, and R. C. Zhang, "Particle swarm optimization," J. Huaqiao University, vol. 27, pp. 343-346, 2006.

[17] F. H. Yu, H. B. Liu, and J. B. Dai, "Grey particle swarm algorithm for multi-objective optimization problems," Journal Computational Application, vol. 26, pp. 2950-2952, 2006.

[18] R. C. Eberhart and J. Kennedy, "Particle swarm optimization," Proceedings of IEEE International Conference on Neural Networks, vol. 4, pp. 1942-1948, 1995.

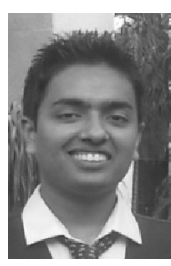

Anshul Gupta was born in New Delhi on 18th November, 1989. He is presently studying in Final year of Bachelor of Technology in mechanical engineering from VIT University, Vellore, India. He did his summer internship in Delhi Metro Rail Corporation, New Delhi, India for 4 weeks in 2010 and in AIESEC Ufa, Russia for 5 weeks in 2011.

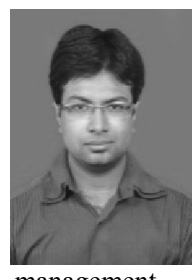

Vishal Narayan, born 8th October, 1990, is pursuing his bachelors degree in mechanical engineering in VIT University, India. He is presently in his final year and has three accepted papers in national and international conferences and journals. He carried out his internship in Nissan Motors (CFAO) Limited, Nigeria in 2010.His areas of interest are operations research and industrial

management.

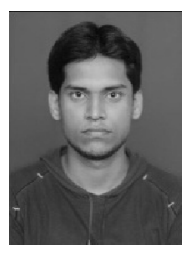

Abhishek Raj is a Final year, Mechanical engineering student in VIT University, Vellore, India. His research interest includes coordination, demand forecasting and inventory management in supply chain. He did his internships for his bachelors degree in Indian Oil Corporation Limited, Barauni, India in 2010.

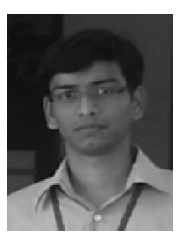

Harsh is a final year student at VIT University, Vellore, India in Computer Science department. His research interests are machine learning techniques, distributed programming and cloud computing.

Nagaraju D obtained his B.Tech in Mechanical Engineering, M.Tech and $\mathrm{Ph} . \mathrm{D}$ in Industrial Engineering from S.V.U College of Engineering, Sri Venkateswara University, Tirupati. He has 11 years of teaching experience. $\mathrm{He}$ has published nearly 10 research papers in refereed national and international journals as well as in national and international conferences. 